\title{
El Nguillatún de los mapuches: Antropología económica de un hecho social total
}

\author{
Erich Bohme Bello ${ }^{1}$ \\ Recibido: 15 de julio de 2013 Aprobado: 27 de septiembre de 2013
}

\begin{abstract}
Resumen
Este trabajo trata con un ritual tradicional de los mapuches, el Nguillatún. Este ceremonial, notorio dentro de las manifestaciones religiosas de esta etnia, contempla en su realización aspectos que, vistos desde una perspectiva material, demuestran en ella la articulación de procesos relativos a la producción, la distribución y el consumo de bienes, es decir trata directamente con la economía y el sustento de esta sociedad en la historia. Consecuentemente, basándonos en sugerencias de Karl Polanyi y Marcel Mauss, en el análisis del Nguillatún podemos advertir aspectos económicos subsumidos en instituciones cuya especificidad es diversa, para notar cómo se manifiesta lo económico en la religión de esta sociedad, siendo la economía un aspecto respecto del que creemos- persiste una gran deuda del mundo académico para con los mapuches.
\end{abstract}

Palabras clave: Mapuches, Nguillatún, Economía, Antropología económica

The Mapuches's Nguillatún:

\section{The Economic Anthropology of a Total Social Fact}

\begin{abstract}
This paper deals with a traditional ritual of the Mapuche, the Nguillatún. This ceremonial, notorious within the religious manifestations of this ethnic group, includes in itself aspects which, seen from a perspective material, evidence in her the articulation of processes related to the production, distribution and consumption of goods, in other words, it deals directly with the economy and the livelihood of this society in history. As a result, based on suggestions by Karl Polanyi and Marcel Mauss, in the analysis of the Nguillatún we can distinguish economic matters subsumed in institutions whose specificity is diverse, just to see how economy manifests itself in the religion of this society, being the economy an aspect for which -we believe- persists a great debt from the academic world to the Mapuche.
\end{abstract}

Key words: Mapuches, Nguillatún, Economy, Economical anthropology

1 Chileno, Magíster en Historia. Profesor de la Escuela de Educación en Historia y Geografía, Universidad Católica Silva Henríquez. E-mail: ebohme@ucsh.cl 


\title{
0 Nguillatún dos mapuches: Antropologia econômica de um fato social total
}

\begin{abstract}
Resumem
Este trabalho trata com um ritual tradicional dos mapuches, o Nguillatún. Este cerimonial, notório dentro das manifestações religiosas de esta etnia, contempla na sua realização aspectos que, vistos desde uma perspectiva material, demonstram nela a articulação de processos relativos à produção, à distribuição e o consumo de bens, é dizer trata-se diretamente com a economia e o sustento desta sociedade na história. Consequentemente, baseando-nos em sugestões de Karl Polanyi e Marcel Mauss, na análise do Nguillatún podemos advertir aspectos econômicos subsumidos em instituições cuja especificidade é diversa, para notar como se manifesta o econômico na religião de esta sociedade, sendo a economia um aspecto referente daquilo que -cremos- persiste uma grande dívida do mundo acadêmico para com os mapuches.
\end{abstract}

Palavras chave: Mapuches, Nguillatún, Economia, Antropologia econômica.

En el presente trabajo presentamos una perspectiva de observación respecto de un ritual practicado por los mapuches que, hasta ahora, no ha sido asumida con propiedad por antropólogos ni por economistas. La práctica ritual en que nos detendremos en lo sucesivo es el denominado Nguillatún.

El Nguillatún, un antiguo ritual de los mapuches, hasta ahora sólo ha sido objeto de análisis como una expresión más de las dimensiones mística y estética de los mapuches (Dowling, 1973; Foerster, 1980, 1993; Foerster y Gundermann, 1996), por lo tanto, sólo tenemos noticias de él como uno de varios rituales de índole religiosa, aún practicados por los miembros de esta etnia. Tampoco existe mención respecto de este rito cuando ha sido revisada la economía de los mapuches (Bengoa, 1984). Hoy esperamos introducir una idea que, sin quitar el trasfondo místico del Nguillatún, de alguna manera nos ayuda a ampliarlo, revisando sus alcances materiales, para así poder reparar en el que continúa siendo el más descuidado de los aspectos humanos de la sociedad mapuche: la economía. ${ }^{2}$

Al respecto diremos que los antropólogos no desconocen la polisemia y las múltiples funciones involucradas en los rituales místicos de las culturas previas

2 El uso del término "económico" responde a la definición sustantiva que de él hizo Karl Polanyi en 1957. Así, entenderemos lo económico como todo lo relativo a la producción, distribución y consumo de bienes necesarios para la producción -y reproducción- de una sociedad (Polanyi, 1994: 126). 
a la llegada de los europeos a América, simplemente han puesto énfasis en los aspectos más evidentemente exóticos de las culturas originarias. A esto se suman otros elementos, como el hecho de que la economía, en ciertas culturas y márgenes temporales -como bien lo ha establecido Karl Polanyi en 1944-, históricamente se ha manifestado formando parte de instituciones sociales plurifuncionales. Así, para el caso que trataremos a continuación, y continuando con la consideración de Polanyi, a la economía de los mapuches la hemos de considerar como "incrustada" (embedded) en la institución social dominante de esta cultura: la religión.

Esto es buena parte de lo que motiva el presente ejercicio, pues si seguimos la invitación que desde la década de 1950 Polanyi nos ha hecho, basta fijar la atención en la institución social dominante de una cultura para poder comprender el funcionamiento de las formas de subsistencia de la misma, esto es, la producción, distribución, y circulación de bienes en esa sociedad. Así, estando ya en el siglo XXI, esto es regla para entender los sistemas económicos de sociedades en las que las formas de circulación de bienes, tanto como la producción y el intercambio, no son tan evidentes como sucede en la cultura occidental, que cuenta con un mercado ya institucionalizado, que como sabemos es, en gran medida, producto de un proceso histórico específico: la Revolución industrial. A este proceso histórico debemos que nuestra Antropología, Historia y Economía, como disciplinas científicas originadas por el modo de vida occidental, no hayan sido capaces sino hasta bien entrado el siglo XIX, de distinguir esas economías "incrustadas" en los mundos indígenas, campesinos, antiguos y medievales.

La Antropología Económica, que es producto por acción tanto por reacción de la obra de Kart Polanyi, desde la primera mitad del siglo XX ha investigado fenómenos relativos al intercambio de bienes y al sustento de las distintas sociedades en el tiempo y el espacio: mientras Occidente expandía su esfera de influencia, la Antropología se consolidaba como herramienta de análisis. Así fueron apareciendo las complejas economías de culturas ajenas y previas a nuestro mundo occidental, con los decimonónicos Lewis Morgan, Friedrich Engels, Karl Marx y hacia fines del siglo XIX con los esfuerzos de Max Weber; los indígenas e isleños en particular, con Marcel Mauss, Franz Boas, Bronislaw Malinowski y Raymond Firth; y los antiguos y prehistóricos, con Karl Polanyi y sus discípulos, Moses Finley y Marshall Sahlins, ya a mediados del siglo XX. Esos esfuerzos marcaron una pauta, que es la que hoy, de manera sencilla y tal vez pedestre, esperamos retomar para observar lo que es y ha sido la subsistencia en la cultura de los mapuches.

Este enfoque, que involucra distinguir aspectos económicos subsumidos en prácticas que se reconocen como manifestaciones de ámbitos que a los occidentales nos parecen a simple vista como no económicos (en este caso específico hablamos de un ritual que se entiende como religioso), claramente 
no es nuevo, y contempla antecedentes ya casi centenarios en los análisis de prácticas rituales mágico-religiosas como el Potlach de los Tlinkit y Kwaikiutl, o los festines de intercambio de los indios Pomo en Norteamérica, hechos por los antropólogos Marcel Mauss, Helen Codere y Alfred Kroeber.

En síntesis, a continuación presentamos el Nguillatún como un ritual que involucra tanto a la religión como a la economía en su celebración. De paso esperamos estimular análisis posteriores realizados ojalá desde la Antropología, para develar con propiedad lo que es y ha sido la economía de los mapuches. Creemos que esta es un área de lo humano que no puede esperar más.

\section{Los mapuches y su pasado: Observación inicial}

Vista desde el ámbito de la historiografía, la historia de los mapuches es un fenómeno relativamente reciente que, como bien plantea José Bengoa en el prólogo de su Historia del Pueblo Mapuche, "continúa construyéndose" (Bengoa, 2000: 7). Ahora bien, aunque esto es efectivo para la labor de los historiadores, cabe señalar que, según nos lo ha sido sugerido en un documento etnohistoriográfico oficial del gobierno de Chile, la historia de estas sociedades (dicha ésta en términos de pasado) no es reciente en cuanto a los tiempos en que los grupos humanos que dieron origen a esta etnia se establecieron inicialmente en el valle longitudinal y la precordillera del centro sur de nuestro país (Gobierno de Chile, 2003: 70). Esto es así, puesto que las primeras manifestaciones materiales de estos grupos de cultivadores sencillos han sido rastreadas hasta alrededor del año 500 de nuestra era, de acuerdo a lo sugerido por estudios arqueológicos (Aldunate, 1996: 111). ¿Qué sucedió con estas gentes durante los mil años que preceden la invasión de los occidentales? No pocos han sido los esfuerzos, mayor o menormente exitosos, para poder dar cuenta de ese vacío, de esa oscuridad, por parte de estudiosos de diferentes áreas. En este sentido, si colocásemos la disputa de la primera mitad del siglo XX entre etnógrafos como Ricardo Latcham y Tomás Guevara en perspectiva, podríamos encontrarnos con que aún en nuestros días permanecen ahí algunas preguntas sin respuestas. Esta dificultad no sólo marca y tiende a dar un carácter especial a los estudios relativos a esta etnia en particular, sino que sugiere al mismo tiempo la necesidad de los especialistas de estar constantemente cuestionándose las perspectivas y metodologías aplicadas en el análisis de sus objetos de estudio. En este sentido, cuando se estudia la cultura de los mapuches se corre el riesgo de elaborar reflexiones -y juicios- que podrían muy pronto verse contradichos. Para algunos esto funciona como un estímulo especial, mientras que a otros esto les hace sentir un tanto inhóspito el tema mapuche como horizonte o campo laboral. 
Evidentemente, no es este el lugar para detenerse a reflexionar sobre los problemas epistemológicos que encierran los estudios de la cultura mapuche, pero al menos podemos decir que para el historiador es imposible aproximarse a los temas relativos a la historia de esta etnia (o a la de los contactos culturales que la han marcado) sin abrazar algunos cuerpos teóricos propios de la antropología a modo de plataforma analítica, en especial de las etnografías profesionales del siglo XX y de los relatos de viajeros durante los siglos previos. En este sentido, si en la actualidad los antropólogos "toman en cuenta la historia de las sociedades que estudian, cuando hay material histórico disponible y cuando este es pertinente para la comprensión del presente" (Beattie, 1972: 40), entonces a nosotros los datos recogidos por los etnógrafos nos son de utilidad en cuanto explican el presente en función de un pasado que ellos, con un método distinto al nuestro (sea éste la historia oral o aquello que Robin Collingwood llamaba historia encapsulada), saben leer.

Una historia de un grupo humano, y más aún de una cultura distinta a la nuestra, hecha desde la perspectiva de cualquier otra que le sea ajena, será infructuosa en cuanto no podrá explicar los valores y las urgencias que mueven a esa sociedad, valores que por lo demás siempre son específicos. Los historiadores -en particular aquellos que practican la etnohistoria y la historia fronteriza- reconocen su deuda con los antropólogos, aunque no sin reparos, puesto que hay profesionales de esa disciplina que pueden ser ocasionalmente poco rigurosos en el tratamiento de los documentos 0 , en otras palabras, de una data histórica que en los casos indígenas suele ser de naturaleza diversa. ${ }^{3}$

Hecha ya esta salvedad, podemos establecer que la cultura de los mapuches es producto de una fusión entre los diversos grupos humanos existentes en la zona central y sur de nuestro actual territorio nacional, los que durante el comienzo de la invasión española -por algunos historiadores aún llamada Conquista (Villalobos, 1983: 71)-, comenzaron a reconocerse a sí mismos en un lenguaje y un cuerpo de creencias comunes, generando así una identidad étnica específica ${ }^{4}$. Estas comunidades habitaban desde el río Choapa hasta la Isla de Chiloé y, como es comprensible, reconocían ciertas variantes culturales

3 El caso específico de la discusión metodológica respecto de la historia de los mapuches puede revisarse en Parentini, 1996: 79-95.

4 En un inquietante trabajo, Tom Dillehay ha cuestionado el rol del contacto cultural entre los grupos humanos que hoy conocemos por mapuches con los invasores españoles. Por una parte, propone que estas sociedades diversas han construido su etnicidad en torno a la figura de los extraños europeos y, por otra, establece que el posterior desplazamiento de estas personas al sistema reduccional habría acentuado paulatinamente la noción que los indígenas tenían respecto de diferencias socioculturales con los chilenos, hecho que habría tenido por efecto una mayor homogeneidad cultural, solidificando así su idea de etnia común. Ver Dillehay, 1990, y Aldunate, 1996: 130. 
según su disposición territorial. ${ }^{5}$ De esta forma se entienden las denominaciones de picunches u hombres del norte, huilliches, los del sur, lafkenches, gentes del mar, y pewenches o gentes del piñón (Grebe, 1998: 55).

Observados desde el punto de vista de la subsistencia, los mapuches se encontraban en un estadio de desarrollo protoagrario (Bengoa, 2000: 23), es decir, conocían la reproducción de ciertas especies vegetales, pero no en gran escala. Esta particularidad probablemente se explique más debido al tipo de organización social que los regía que al estadio de desarrollo material que detentaban, no olvidemos que los avances técnicos normalmente se materializan como respuesta a una necesidad social objetiva (White, 1964: 337-363). Más allá de este problema teórico, el estado del conocimiento respecto de la forma en que los mapuches sustentaban su existencia en tiempos de la invasión europea nos indica que estos cultivaban papas (Wolf, 1990: 65), además de consumir pencas, ají, piñones, carne de guanaco, algunos moluscos, peces, como también algún tipo de cereal actualmente desconocido o desaparecido. Y si bien los medios de subsistencia mapuche previos al contacto cultural con los peninsulares no han sido completamente determinados, podemos afirmar, en base a revisión de una tesis de antropología de 1980 (Foerster, 1980: 71-79), que la ganadería y los cultivos extendidos serían más bien producto de algún aprendizaje obtenido en dicho contacto. En lo que respecta a la esfera técnica, no obstante la adopción del caballo (Ortiz, 2003; Villalobos, 1989: 43-63), el soporte tecnológico de esta sociedad era más bien exiguo, destacándose algunos utensilios de madera y algunas mínimas piezas de metal, tal vez introducidas por contactos con culturas del norte del actual territorio chileno. Junto a esto cabe señalar que -tradicionalmente- eran las mujeres quienes se encargaban de los cultivos, aunque las faenas más duras eran colaboradas por los hombres (Villalobos, 1983: 72).

La organización política de los mapuches, que tan compleja pareció a los europeos del periodo, estaba subsumida a una entidad dominante: el parentesco, una institución tanto o más importante que la religión para estos grupos humanos. Las comunidades -cuyo patrón de asentamiento era disperso (Aldunate, 1996: 123)- llevaban el nombre de Lof y sus miembros tenían, normalmente, lazos parentales entre sí, hecho que se manifestaba en la erección de un Rewe común y en el desplazamiento de autoridad a un Lonco. Ahora bien, no obstante estos grupos contaban -y cuentan- con líderes, aún es de destacar el hecho de que "a diferencia de las sociedades andinas, el sistema social mapuche era predominantemente igualitario" (Aldunate, 1993: 130). Asimismo, la familia mapuche, algo diferente de nuestra

5 Entendemos por comunidad en el sentido en que Tönnies (1887) la postula, distinta de la noción de sociedad. (Tönnies, 1971: 295-296). 
noción occidental de ella (aunque igualmente patrilineal), era el centro de la comunidad y sólo en ella se ordenaba tradicionalmente la división social del trabajo. ${ }^{6}$

Más allá de lo anterior, sorprende el hecho de que los mapuches jamás articularon aldeas, ni grandes ni pequeñas. Ellos prefirieron, en cambio -como plantea María Ester Grebe-, organizar el asentamiento rural de cada familia en conjuntos cercanos o lejanos de acuerdo a su relación filial. Ahora bien, todas las formas en que se articulaban estos grupos, incluso en su trabajo, tenían una explicación basada en un relato sobrenatural. En este sentido, diremos que la estructura mítico-religiosa, tan determinante en el caso particular de esta etnia, es bastante compleja como para detenernos a explicarla en este papel. Sólo hemos de tenerla presente como un dispositivo cultural preponderante que les ha permitido a estas personas explicarse el cosmos y, al mismo tiempo, subsistir regulando o sistematizando su interacción con él.

Los mapuches, como ha ocurrido con todos los grupos sociales en el transcurso de la historia, han debido resituarse y reinterpretarse ante los desafíos que acontecimientos de naturaleza diversa les han propuesto en su devenir. No es nuestro objetivo detallar estos procesos, pero sí el establecer que su cultura (sobre todo las manifestaciones éticas de ésta) ha sufrido un tipo de erosión en el contacto con Occidente que, sin embargo, aún no ha podido dar cuenta completamente de ella. Ahora bien, con respecto a nuestro propósito y no obstante esto último, es necesario establecer que resulta ser notable que en zonas rurales del sur de nuestro país hay prácticas ancestrales de los mapuches como la del Nguillatún que han seguido practicándose, incluso hasta hace sólo un par de décadas de manera sorprendentemente apegadas a lo acostumbrado en el siglo XVIII y XIX. Téngase en cuenta que, al no contar con evidencias anteriores a dicho siglo, no podemos decir con propiedad que es altamente posible que la celebración de este ritual sea históricamente aún más arraigada de lo que en nuestros días se cree.?

Estando ya expuesta nuestra apreciación general respecto de la etnia mapuche como grupo humano y como problema etno-historiográfico, a continuación articularemos una descripción y análisis del Nguillatún, haciendo especial nota de sus alcances materiales, es decir, de aquello que le es esencial

6 Marcelino Linconao, pewenche, nos habló de algunas diferencias notables en los ejemplos de su abuelo y uno de sus primos. En su relato destaca el hecho de que su abuelo (que debería haber nacido en el siglo XIX) tenía tres esposas y más sorprendente aún es saber que en la actualidad su primo tiene dos viviendo bajo el mismo techo (Linconao, 2006).

7 Cabe destacar que en la actualidad, incluso en el Gran Santiago, aún se llevan a cabo ceremonias de esta naturaleza por miembros de esta etnia. 
y que influye fuertemente -aunque sumergido en un entramado de naturaleza religiosa- en la subsistencia y la reproducción de estas comunidades.

\section{El Nguillatún de los mapuches: Introducción al problema}

En principio, resulta necesario establecer que nuestra descripción del tradicional ritual del Nguillatún descansa, esencialmente, en el uso de los testimonios de dos informantes mapuches, Sebastián Coña (52, Nueva Imperial) y Marcelino Linconao (51, Vilcún). Estas evidencias, a las que hemos sido expuestos verbalmente, se suman a un conjunto de fuentes impresas, que van desde el testimonio clásico del Lonco Pascual Coña, anotado en 1929 por el religioso capuchino, padre Ernesto de Moesbach, hasta los trabajos actuales de los antropólogos Hans Gundermann y Rolf Foerster. De igual manera, necesario también es reconocer en dos planteamientos esenciales de Maurice Godelier a las ideas que nos han impulsado a cuestionarnos sobre el papel que el Nguillatún ha jugado en todo aquello relativo al problema del sustento de los mapuches. Este intelectual francés ha dicho en 1973 que en definitiva "la materia prima de lo divino, de lo sagrado, [es la] articulación oculta de las relaciones sociales y de las condiciones de reproducción del sistema social en el seno de un medio natural determinado" (Godelier, 1978: 350). La segunda proposición, hecha en 1984, es la siguiente: "Human beings, in contrast to other social animals, do not live in society, they produce society in order to live" (Godelier, 1988: 7).

Que los seres humanos deban generarse una sociedad en función de mantenerse con vida es uno de aquellos hechos tan evidentes que rara vez nos cuestionamos al respecto. Ahora bien, la situación de los mapuches en esta esfera es de especial interés dada la complejidad de los dispositivos culturales que entran en escena cuando se trata de articular sus ciclos productivos. En este sentido, la comprensión de los fenómenos relativos a la economía de las comunidades mapuches se ha visto dificultada, esencialmente, debido a que antes del contacto con españoles (y durante varios siglos posteriores) esta cultura no contaba con instituciones específicamente económicas, como sí sucede con nuestras actuales sociedades occidentales. Siendo esto así, nos resulta muy pertinente recordar la tesis de Karl Polanyi, quien en los años 40 estableció que "man's economy, as a rule, is submerged in his social relationships" (Polanyi, 1968: 7).

Que la economía esté incrustada en las relaciones sociales de los hombres implica que los actos y hechos relacionados con la producción, la distribución y el consumo de bienes necesarios para el sustento de las sociedades pueden -como efectivamente sucede en el caso de los mapuches- encontrarse su- 
mergidos en prácticas o costumbres no económicas. En otras palabras, lo que se observa en estas comunidades es que, tradicionalmente, lo económico no puede entenderse (ni tampoco manifestarse) fuera de la esfera de la religión o el parentesco (Polanyi, 1944: 129). Esto es de especial interés para nuestra reflexión, puesto que el Nguillatún es un ritual en el que se entrelazan todos los fenómenos y aspectos profundos de lo humano: lo mágico-religioso, lo jurídico, lo económico, lo estético y lo político. En definitiva, como acontecimiento social, este ceremonial mapuche bien cabe en el concepto de Fait socieaux totaux ("hecho social total") propuesto en 1923 por Marcel Mauss en su clásico Essai sur le Don (Mauss, 1991: 259). Volveremos a estas últimas ideas tan pronto consigamos adentrarnos en la observación del Nguillatún propiamente tal.

\section{Aspectos del rito y su práctica: Descripción general}

Mirada desde un punto de vista diacrónico, la cultura de los mapuches, como ya lo hemos sugerido anteriormente, ha generado distintos tipos de instituciones y dispositivos socioculturales tanto para mantenerse con vida, como para producirse y reproducirse en el tiempo. Uno de estos mecanismos simbólicos es el Nguillatún, un ritual intercomunitario en el que se intenta propiciar a las divinidades, en este caso específicamente a su dios creador, Nguenechén (Gundermann, 1981: 30) o Ngenchén (Latcham, 2001: 45).

Desde el punto de vista etimológico, en Mapudungún "nguillatu" es pedir, mientras la " $n$ " indica el acto de. Pues bien, para los mapuches el Nguillatún es un ritual en el que piden a Nguenechén por sus cosechas, por lluvias (o por el cese del mal tiempo) y por el bienestar general del grupo. En este sentido, mientras a los profanos esta institución se les presenta como un complejo ceremonial marcado por diversas acciones difíciles de comprender, para los mapuches esta es "la fiesta más solemne" que poseen (Pascual Coña, 1995: 372; S. Coña, 2006) y, más aún, esta sigue siendo "la más amplia congregación pública en funcionamiento dentro de la sociedad mapuche" (Dillehay, 1990: 82).

Existe entre estas gentes un relato mítico que explica el origen del NguiIlatún. Este dice relación con la muerte de dos hombres que intentaron cruzar el río Toltén, cuyos cuerpos no podían ser recuperados por sus respectivas familias. Desesperanzados, los familiares de estos hombres recurrieron a una kalku (hechicera) para poder tener los cuerpos de regreso, pero no pudieron cumplir con lo requerido a tiempo, hecho que desencadenó la ira de la bruja, que los transformó en espíritus malignos y los mantuvo en el volcán Villarrica, lugar desde el que causarían sequías o inundaciones. Cierto día, los dolientes, por su parte, se encontraron con dos aves sin nombre, las que, conmovidas por la pesadumbre de estas gentes, tomaron los nombres de Tramaleufu 
y Winkaleufu y prometieron romper el maleficio. Esta oferta, como es de esperar, sólo tenía un requerimiento: que luego de solucionar el problema ellos celebraran un Nguillatún (Foerster y Gundermann, 1996: 233).

Más allá del estudio relativo a los orígenes míticos de esta institución, esta rogativa ceremonial no tiene, según lo que los informantes y la evidencia documental nos han hecho saber, tiempos fijos en el año para ser ejecutada. Los rangos temporales de realización varían entre las diferentes comunidades y épocas, pero esto es así, sobre todo, porque su ejecución responde indistintamente a acontecimientos concretos o sobrenaturales de naturaleza contingente. ${ }^{8}$ Por eso, en el contexto de una necesidad, efectivamente es el Lonco quien convoca a un Nguillatún y muy usualmente también es quien sabe cuál es el momento más indicado para hacerlo. Consultados por el qué hace al Lonco conocer el momento, nuestros informantes-Marcelino y Sebastián-, nos explican que aparecen signos evidentes en el entorno. La sensación climática se percibe como seca y muy cálida, el río ha disminuido su caudal, las siembras se ven complicadas por insectos u otro tipo de plagas o la escasez potencial de bienes de consumo se les hace notoria. Para el caso de una sociedad estructurada en función de la autosuficiencia como históricamente lo ha sido la mapuche (Stuchlik, 1974: 17, 62 y ss; Ortúzar, 2005), esto representa derechamente un temor que involucra la subsistencia. Para nosotros se trata de una preocupación de naturaleza económica.

Otra manera de saber cuándo es necesaria la celebración de este ritual involucra necesariamente a la machi y es, ante todo, un asunto sobrenatural. La machi, que puede indistintamente ser mujer u hombre, es la única persona en el grupo que domina el lenguaje de lo inmaterial (el discurso ritual) y es "la principal portadora y transmisora de la religión mapuche" (Grebe, 1998: 60). Esta dominadora del discurso chamánico, puede conocer el momento propicio para realizar un Nguillatún por medio de los peumá (sueños) o por la interpretación de los perimontún, portentos que pueden ser el nacimiento de algún animal mal formado o bien otros signos en que acontecimientos ordinarios manifiesten alguna suerte de distorsión. En estos, la machi puede recibir la información por medio de parientes fallecidos que "hacen las veces de emisarios de mensajes divinos" (Gundermann, 1981: 27).

La convocatoria para ir adelante con la celebración de este ceremonial -solemne y socialmente siempre bienvenida- supone una serie de requerimientos. Las formalidades del Nguillatún hacen necesarias una vestimenta

8 Hemos podido notar que en las comunidades cercanas a Nueva Imperial las celebraciones del Nguillatún en la actualidad pueden superar un año de intermedio, mientras que en localidades como Vilcún y Cauñicú, según lo indican nuestras fuentes (que se distancian una de otra en treinta años), los rangos de tiempo varían entre tres veces al año y uno cada diez. 
adecuada o, puesto en otros términos, de acuerdo a lo que el Lonco estime apropiado. Esto, además de implementos como un fondo para cocinar, leña en cantidades necesarias y pequeñas fuentes y vasijas. Más importante aún es notar que, con motivo de aquello que se debe ofrendar, compartir y consumir, las familias asistentes ese día tengan consigo en el fogón todos los alimentos que tengan en casa. En este sentido, la puesta en práctica del ritual requiere que se lleve todo lo que uno tiene, porque a Nguenechén no puede negársele lo que él, indistintamente, ha hecho posible (S. Coña, 2006).

El lugar sagrado en el que se realiza el Nguillatún es llamado Lepún, voz mapuche que denota un espacio físico y simbólico (Gundermann, 1981: 32). Esto es una superficie relativamente circular u ovalada (cuyo tamaño promedio tiene usualmente entre 20 y 30 metros de diámetro), abierta hacia el este y en cuyos márgenes se reúnen las diferentes familias en torno a fogatas en las que cada una cocina cuando el Lonco así lo indica pertinente. En el centro de este sitio se encuentra el Rewe, tronco de roble (u ocasionalmente también de maqui, según el testimonio recogido por Fray F. J. de Augusta) al que se le ha dado la forma de una escalera que termina en una suerte de cabeza antropomorfa. Desde la perspectiva lingüística, los antropólogos han establecido que para los mapuches "Re" es algo puro o exclusivo y "we" es lugar o espacio (Foerster, 1993: 93), destacándose así la imagen pulcra que de este poste sagrado tienen estas comunidades. Al respecto, particularmente sorprendente es el hecho de haber escuchado a ambos informantes referirse indistintamente al Rewe como "cruz" (S. Coña, 2006: Linconao; 2006), dejándonos ver en ello un sensacional ejemplo de superposición de creencias, por esto es común que para explicar el Rewe y sus funciones religiosas se hable de altar principal. Con todo, este poste sagrado se acompaña de árboles pequeños (canelo y maqui, aunque esto varía regionalmente) y es el lugar específico para realizar las ofrendas y donaciones; cualquier otra actividad que se realice en este lugar representa una profanación. Asimismo, al oriente del Lepún puede erigirse también un altar secundario, el llamado Ilangi-llangi, que normalmente es hecho de ramas de árboles como maqui, laurel, manzano o, preferentemente, el canelo, árbol sagrado característico de los mapuches (Augusta, 1991: 207; Aldunate, 1986: 86).

Durante la práctica de la rogativa, los actos rituales desarrollados alrededor de Rewe son repetidos en forma constante, repetitiva y sorprendentemente simétrica, siempre en sentido contrario al de las agujas del reloj. En el Nguillatún los participantes van alternando bailes como el Masatún y el Tregilpurún, además del Amupurún, normalmente asociado a la mujer. Asimismo, y como pronto veremos, la mala ejecución de algún aspecto de este rito podría molestar a Nguenechén. Es para evitar esto que, en medio de dichas acciones, se ofrecen distintas libaciones, se sacrifican corderos y se los sangra a un costado del Rewe, se lanzan gritos purificadores (awún) y se 
bebe el Mudai (bebida ceremonial tradicional de los mapuches), que ocasionalmente se sopla o escupe al aire, emulando el efecto de la lluvia, hecho que marca simbólicamente un acto en el que se perpetúa el dar-recibir-devolver entre los humanos y el creador del mundo, algo que inmediatamente nos remite a la articulación de la Ley del Don, señalada en el primer cuarto del siglo XX por Marcel Mauss.

Ahora bien, siendo el Nguillatún un rito en el que literalmente las comunidades mapuches se juegan la vida, la ejecución de este debe seguir ciertas reglas. Estas son objeto de especial preocupación para el Lonco. Si alguien baila mal, come antes de tiempo, lleva vestimentas impropias, refleja actitudes egoístas o se comporta de manera imprudente, es sancionado físicamente. Esta es tarea del Welkén, ayudante del Lonco, quien, provisto de una varilla, golpeará a quien infrinja las reglas del rito o lo despojará de pertenencias y alimentos arrojándolos al suelo. Es notable el hecho que, tradicionalmente (y contrario a lo que sucede en la actualidad), no se permita a los participantes llevar joyas, anteojos o relojes. La explicación para esto radica en que en aquellas rogativas que tiene por fin evitar la aridez y el excesivo brillo del sol el resplandor de ciertos objetos es contraproducente con el motivo del ritual. Asimismo, se nos ha hecho notar que, cuando aquello que se pide tiene que ver con la bonanza de estas comunidades, la vestimenta debe ser clara o blanca, mientras que cuando aquello que se persigue es la lluvia, esta debería ser de colores.

El significado de los colores y su uso en el contexto resulta ser de especial interés. Mientras los testimonios orales y escritos nos hablan del uso de banderas blancas y negras en un sentido como el anteriormente descrito, Jorge Dowling comenta que "es tanta la fe que ellos [los mapuches] tienen del poder de estos colores sobre el destino de las cosas y de las personas que su presencia constituye un buen augurio y es por eso que los animales y flores de color blanco y azul son respetados y venerados" (Dowling, 1973: 74). En todo lo relativo al colorido de atuendos, indumentaria y objetos de culto involucrados en el Nguillatún, la práctica es tan rigurosa, que "no hay momento alguno en el cual [los participantes] tienen iniciativa propia o libertad de acción, excepto, quizás, al despedirse, agradecer y marcharse" (Gundermann, 1981: 100).

No obstante lo anterior, según sabemos, en la realización del Nguillatún la comunidad entera tiene participación activa, aunque, a pesar de este hecho, los roles litúrgicos y de regulación recaen sobre tres personajes en particular. Si bien el Lonco hace sentir en todo momento su autoridad, diremos que los roles más destacados en la puesta en práctica del ritual son los de la machi y el Nguenpín, prestigioso anciano director del rito (Augusta, 1991: 208). El caso de la machi es particularmente interesante, puesto que, al contener en sí misma experiencias y conocimientos sobrenaturales, conoce los aspectos 
tradicionales de la celebración y, al mismo tiempo, sabe cómo se debe hacer para adecuar las rogativas a una situación específica de la comunidad. Es así que en las diferentes etapas del ritual (oración, bailes-sacrificio y banquete) ella cumple con diversas tareas litúrgicas, tales como ir dejando ofrendas en cada uno de los escalones del Rewe mientras lo asciende progresivamente. En este, que es el momento más álgido de la rogativa, la machi, al alcanzar el extremo del poste sagrado, ejecuta su baile, el ngueicurehuenn (término que hace relación con "mecer el Rewe"), y establece contacto con Nguenechén, para luego dejarse caer y ser recibida en las mantas de hombres, de modo de evitarse daños físicos de seriedad (Dowling, 1973: 74).

En lo que respecta a la práctica propiamente tal del ritual, cuando las invocaciones han sido efectuadas de acuerdo a lo establecido por la tradición, aparecen, como característica, una serie de fenómenos que llaman poderosamente nuestra atención. No sólo los participantes en los bailes llevan consigo comida (sopaipillas, carne de cordero y caballo, maqui y mudai) que intercambian indistintamente -y que consumen durante la fase de rogativa-, sino que, cuando el Lonco así lo indica, se inicia un asombroso banquete de donaciones llamado Katrünelëmn, que es como se denomina en este contexto al acto de la distribución o reparto recíproco de comida y bebida (Augusta, 1991: 4), el mismo que Pascual Coña llama "comilona" (P. Coña, 1995: 389). Al respecto, de especial interés son las prácticas documentadas por Fray F. J. de Augusta. En sus Lecturas Araucanas, este religioso comenta que el "Konchotún es la mutua entrega de la carne del cordero hecha de la manera indicada; cuya consecuencia es que las dos personas que la han manejado, quedan unidas en adelante por una especie de amistad, llamada konchowen y se saludan para siempre elmi koncho, tú koncho" (Augusta, 1991: 3). Así notamos uno de los propósitos inmediatos del intercambio de donaciones que se articula en el Nguillatún.

Así, en el banquete se articula un proceso extendido de reciprocidad generalizada. Por supuesto, y como ya hemos establecido con anterioridad, cada familia situada en uno de los muchos fogones localizados en el contorno del Lepún ha llevado a la celebración del Nguillatún la totalidad de los bienes de consumo que poseen. Por esto el volumen de comida disponible involucrada supera siempre la capacidad de consumo de los asistentes, incluso de los invitados y espectadores del Nguillatún. Esto implica que, si bien parte de los manjares intercambiados terminan regados en el Lepún, las gentes comen en volúmenes desacostumbrados cantidades de cordero, piñones, sopaipillas, mote y papas, además de beber el mudai que llevan en los metahues, o cántaros sagrados.

Interesante -y paradójico- es también que la tradición obligue a estas personas a gastar todo lo que tienen, cuando la rogativa que están articulando tiene, por motivo esencial, el asegurarse por mediación divina el 
sustento o bienestar material, léase este en términos de su significado para estas sociedades: comida. Ahora bien, si la usanza condiciona a los mapuches a derrochar en forma de compartir su stock alimenticio con sus pares y a elevar una parte no necesariamente menor en ofrendas a las divinidades, aparece, a modo de prohibición, algo tal vez aún más sorprendente. Una vez concluida la ceremonia (hecho que supone la extinción de todos los fogones), los participantes no pueden llevar nada de regreso a casa, o al menos -como se nos ha hecho saber- nada que les haya pertenecido previamente (S. Coña, 2006; Linconao, 2006). Es decir, si algunos llevan comida de vuelta esto sólo es socialmente aceptable si ésta les ha sido donada (Linconao, 2006).

Ahora bien, vistas desde el ángulo de la observación económica, estas costumbres hablan tanto o más del trasfondo socioeconómico del Nguillatún que su misma naturaleza de rito agrario-religioso. En este sentido, más allá de lo que puede observarse en la superficie de estas frondosas prácticas simbólicas, el Nguillatún es, ante todo, un complejo sistema de significaciones (Foerster y Gundermann, 1996: 210). En él, los gestos, acciones, discursos y oraciones -incluso los objetos involucrados- poseen un carácter significativo y simbólico definido. Por esto mismo podemos entender que la ceremonia se desarrolle en medio de un tiempo ritual que por definición escapa a la noción temporal ordinaria de estas comunidades; ésta es siempre una fecha excepcional para los mapuches (Eliade, 1996: 63 y ss). Al colocar esto último en perspectiva nos es posible entender por qué "el rito se diferencia del tiempo no-ritual por la oposición escasez/abundancia y comunitario/familiar" (Foerster, 1993: 97).

La anterior observación, hecha hace algunos años por el profesor Rolf Foerster, nos permite notar que los días de Nguillatún vienen a romper el tiempo no-ritual en cuanto, muy diferente al diario acontecer de estas personas, el consumo de bienes de subsistencia (alimentos) se lleva a cabo de forma exagerada, llegando al derroche de ellos. El Nguillatún, de esta manera, marca entonces una etapa de reciprocidad generalizada, de dilapidación y al mismo tiempo de profunda entrega religiosa.

\section{Análisis material del fenómeno}

La anterior descripción del Nguillatún nos obliga a considerar un aspecto fundamental: que este rito es, en el fondo, una celebración eficaz en lo que respecta al ánimo y espíritu del grupo y que, sobre todo, "se materializa en la abundancia de alimentos compartidos" (Foerster, 1993: 97). Es por esto que la noción del Hecho social total de Marcel Mauss se nos presenta como una primera instancia teórica para comprender mejor qué es el Nguillatún en términos simbólicos, particularmente su implicancia material, es decir en 
aquello que toca la forma en que estos grupos han sostenido su existencia en el tiempo.

Uno de los fenómenos asombrosos en el Nguillatún es el notar cómo el sacrificio (de especies, de animales o, incluso de humanos ${ }^{9}$ ) se caracteriza por el hecho de que aquello que se "sacrifica" sufre un proceso de sacralización que lo separa irremediablemente de la esfera de lo profano. Mediante esto entendemos que aquello por lo que se eleva la rogativa es pagado o devuelto por la comunidad a Nguenechén en el acto del sacrificio propiamente tal. Si lo observamos nuevamente bajo la óptica teórica de Mauss, notamos que hay un Don que es (y debe ser) devuelto en un Contra-don y que eso representa un elemento fundamental en la articulación de la economía de los mapuches. En otras palabras, los mapuches hacen un sacrificio al deshacerse de sus bienes de subsistencia para, valga la paradoja, asegurar su sustento, que retorna en la benevolencia del creador que devuelve su don permitiendo condiciones climáticas favorables que, al final del camino, les asegura buenas cosechas.

Estas características sociales inmersas en el rito nos permiten entender que el Nguillatún es, en el fondo, un acontecimiento que otorga sentido a la vida social de las comunidades mapuches debido a que, develado, nos refiere a un problema que es esencialmente económico. Y esto no sólo debido a que las rogativas normalmente tienen relación con el clima y las cosechas como lo hemos señalado anteriormente, sino especialmente porque, como práctica, se limita a -esto dicho en los pertinentes términos etnocentristasmarcar etapas productivas.

Esta última observación está vinculada a ideas implícitas en observaciones que Bronislaw Malinowski hizo hace casi un siglo, mientras estudiaba los ritos agrarios y la magia de los trobriandeses (Malinowski, 1976). Al respecto, en un estudio conmemorativo posterior respecto de la producción de Malinowski como una unidad, se ha dicho que para este antropólogo prácticas como las señaladas se utilizaban dentro de ese contexto cultural particular como señales para organizar y dotar de un orden y una lógica específica a las actividades agrícolas que allí realizaban (Nadel, 1974). Esto es algo que de alguna manera nos parece similar a lo que acontece con los mapuches y su Nguillatún y, creemos, debería tenerse en cuenta para análisis posteriores.

Uno de los muchos fenómenos que podrían llamar la atención de alguien ajeno a las costumbres de estas comunidades, es el hecho de que en la práctica propiamente tal del Nguillatún los bienes de subsistencia son con-

9 El último sacrificio humano del que exista registro en una ceremonia de esta naturaleza, aunque algo verdaderamente poco usual, ocurrió en mayo 1960, luego del gran terremoto de ese año (Dowling, 1973: 77). 
sumidos en abundancias groseras y derrochados indiscriminadamente. Esto sucede con motivo de que sea posible dar por cuenta con todo el excedente (o riqueza a ojos de un occidental medio) acumulado por esas comunidades para, una vez perdido, activar un nuevo ciclo productivo. Un economista formal diría que esta práctica es, en el fondo, una forma artificial de crear escasez para incentivar al grupo a emprender un proceso productivo nuevo y más eficiente. Ahora bien, no obstante lo anterior, y aunque la finalidad material del rito tiene dicha particularidad, su calidad de dispositivo cultural nos recuerda que, como acto, este siempre es inconsciente; en este sentido, no olvidemos que "la cultura no deriva de la actividad racional de los individuos" (Sahlins, 1997: 9).

Otra particularidad sumergida en el Nguillatún es que, más allá del marcar (y estimular) el inicio de una nueva fase productiva, el que en esta ceremonia se gasten los bienes de la comunidad en un festín, implica que las diferencias sociales y las emociones antagónicas basadas en la posesión de excedentes y en la acumulación sean exitosamente resueltas en la práctica misma de este ritual. En este sentido, un rol que no ha sido reconocido en el Nguillatún de los Mapuches es el de la particularidad que tiene de tornarse en una suerte de ecualizador o, más bien, en un elemento perpetuador del orden social tradicional, asegurando una convivencia menos inclinada hacia conflictos interpersonales o entre las unidades domésticas. Esto es así porque su celebración tiende a igualar a las familias en términos de sus posesiones materiales de modo que las diferentes suertes de cada uno no se hagan permanentes ni más profundas. Todos gastan durante el banquete todo lo que tienen, sin importar si algunos fogones tenían más comida u otros bienes de consumo que perder. En ese sentido es un igualador social, pero, más que eso, lo que el Nguillatún hace es perpetuar la estructura y forma social vigente. Así, evitando la riqueza de unos en desmedro de otros, reafirma el status superior del Lonco y la machi.

En relación a lo recientemente planteado, para el teórico húngaro Karl Polanyi, la solidaridad de una tribu (como a nuestros ojos ha ocurrido históricamente con los mapuches, y muy a pesar de la polémica que en la actualidad rodea al uso del concepto tribu ${ }^{10}$ ), se encuentra muy usualmente "cimentada en una organización de la economía que actúa para neutralizar los efectos destructivos del hambre y del deseo de ganancias, mientras que explota al máximo las fuerzas solidarias inherentes a un destino económico común" (Polanyi, 1994: 130).

10 Las polémicas entre Maurice Godelier, Elman Service y Marshall Sahlins pueden revisarse en Bonte, 1996: 716. 
De acuerdo a lo anteriormente planteado, el rol social del Nguillatún nos recuerda en cierta medida -por cuanto en él se manifiestan la abundancia y el derroche de los que para nosotros son bienes de consumo- a algunas ceremonias tan exóticas como la del Potlach de los Kwaikiutl o los antiguos festines de intercambio de los indios Pomo en la América del Norte, en los que la donación recíproca y la dilapidación de bienes van dando forma a sus sociedades. ${ }^{11}$ Ahora bien, tanto como ocurre con el análisis material de los rituales anteriormente mencionados, bueno es tener en cuenta que algunas nociones occidentales como la propiedad de la tierra, el trabajo, la acumulación o la racionalidad económica, son inaplicables para la comprensión de los fenómenos materiales de los mapuches, y esto incluso hasta el siglo XX. Esto último nos muestra el tamaño de la barrera cultural que históricamente ha separado a la Economía formal de comprender, por ejemplo, qué sucede con la elección racional cuando un comunero vierte el contenido de su vaso en la tierra en medio de un Nguillatún y, más aún, qué ha sucedido en la historia con las formas en que los indígenas organizan sus sustento. La Antropología, por otra parte, si bien reconoce resultados en análisis realizados en otras áreas culturales, todavía tiene deudas, y esta respecto de los mapuches es clara y se manifiesta en la inexistencia de estudios específicos respecto de su economía.

\section{Conclusiones}

La comprensión del rol del Nguillatún en el sustento de los mapuches sólo es posible si se realiza un análisis institucional sustantivo, cosa sugerida por Karl Polanyi a partir de su obra de 1944, La Gran Transformación, en la que se indica que la economía está incrustada en las relaciones sociales, en dispositivos culturales plurifuncionales. Así, para comprender la naturaleza y el funcionamiento de una economía sin mercado como la de los mapuches, el análisis institucional nos obliga a identificar, como paso inicial, cuáles son las instituciones dominantes de una sociedad, en este caso, la religión. Esto implica que para poder entender el funcionamiento de la economía de los mapuches es necesario conocer, primero, cómo opera su religión y de qué manera ésta se manifiesta en la comunidad. De ahí en adelante podemos ver que los mapuches carecen de instituciones específicamente económicas y que el problema del sustento lo han resuelto históricamente en otras esferas, siendo una de ellas el Nguillatún. Para esto usamos la plataforma teórica de Karl Polanyi, por largas décadas disponible y por otras tantas ignorada. Y esto incluso por nuestros amigos, los antropólogos.

11 Como referencia de estos ceremoniales indígenas tradicionales pueden consultarse los trabajos ya clásicos de Philip Drucker y Andrew Vayda disponibles en Dalton, 1967: 481-500. 
El Nguillatún, asombroso ejemplo de hecho social total, es un fenómeno complejo en el que los mapuches se han reinventado como sociedad, como detentores de un conjunto de valores particulares y, en último término, como etnia específica. No sólo es uno de los sistemas de solidaridad interna que les permite seguir viviendo (Bengoa, 1984: 243), sino también seguir haciéndolo en armonía, y continuar conviviendo pacíficamente con el cosmos al obtener de él una afirmación sobrenatural -o metafísica- de su propia existencia. Así entendemos la presencia de un Mapu y un Wenumapu en la cosmovisión que marca las decisiones que se manifiestan en las mentes de estas personas.

Finalmente, creemos que una comprensión profunda de los fenómenos sociales de los antiguos y actuales mapuches nos permite, en perspectiva, no sólo conocer los aspectos exóticos de gentes que viven al sur de Santiago, en reducciones que a veces nos son difíciles de entender, sino además maravillarnos con la riqueza de formas alternativas que las distintas culturas tienen para enfrentarse con su entorno físico y social. En último término, conocer estas particularidades nos ayuda a entender un poco más a los mapuches y también, por qué no decirlo, a comprender que en la historia de la humanidad no ha habido "economía", sino más bien, "economías", poniendo énfasis en el plural del término.

\section{Referencias}

\section{Fuentes primarias}

\section{a.- Entrevistas}

Sebastián Coña, enero-febrero de 2006, Nueva Imperial.

Marcelino Linconao, octubre de 2006, Vilcún.

\section{b.- Impresos}

AUGUSTA, Fray F. J. de (1991). Lecturas Araucanas. Temuco: Editorial Kushe.

COÑA, P. (1995). Testimonio de un Cacique Mapuche. Santiago de Chile: Pehuén.

\section{Fuentes secundarias}

ALDUNATE, C. (1986). Cultura Mapuche. Santiago de Chile: Mineduc.

ALDUNATE, C. (1996). "Mapuche: gente de la tierra", en: Hidalgo, Jorge; Schiappacasse, Virgilio; Niemeyer, Hans; Aldunate, Carlos; Mege, Pedro (editores). Etnografía: Sociedades Indígenas Contemporáneas y su Ideología, tomo II. Santiago de Chile: Editorial Andrés Bello. 
BENGOA, J. (2000). Historia del Pueblo Mapuche. Siglo XIX y XX, Santiago de Chile: LOM.

BENGOA, J. (1984). "La Economía Comunal Mapuche", en Revista Cultura, Hombre, Sociedad. №1, 1984. Universidad Católica de Temuco.

BEATTIE, J. (1972). Otras Culturas. Objetivos, Métodos y Realizaciones de la Antropología Social, México: Fondo de Cultura Económica.

BONTE, P. (1996). "Tribu", en: Bonte, P.; Izard, M. (editores). Diccionario Akal de Etnología y Antropología. Madrid: Akal.

DALTON, G. (ed.) (1967). Tribal and Peasant Economies. Readings in Economic Anthropology. New York: Natural History Press.

DILLEHAY, T. (1990). Araucanía: Presente y Pasado. Santiago de Chile: Editorial Andrés Bello.

DOWLING, J. (1973). Religión, Chamanismo y Mitología Mapuches. Santiago de Chile: Editorial Universitaria.

ELIADE, M. (1996). Lo Sagrado y lo Profano. Colombia: Editorial Labor.

FOERSTER, R. (1980). Estructura y Funciones del Parentesco Mapuche. Tesis para optar al grado de Licenciado en Antropología Social. Santiago de Chile: Universidad de Chile.

FOERSTER, R. (1993). Introducción a la Religiosidad Mapuche. Santiago de Chile: Editorial Universitaria.

FOERSTER, R.; Hans GUNDERMANN (1996). "Religiosidad Mapuche contemporánea", en Hidalgo, Jorge; Schiappacasse, Virgilio; Niemeyer, Hans; Aldunate, Carlos; Mege, Pedro (editores). Etnografía: Sociedades Indígenas Contemporáneas y su Ideología, tomo II. Santiago de Chile: Editorial Andrés Bello.

GODELIER, M. (1978). Economía, Fetichismo y Religión en las Sociedades Primitivas. México: Siglo XXI.

GODELIER, M. (1988). The Mental and the Material. London: Verso.

GOBIERNO DE CHILE (2003). "Los Mapuche en la historia y el presente", en: Informe de la Comisión de Verdad Histórica y Nuevo Trato de los Pueblos Indígenas. Documento en tres volúmenes entregado a S.E. el Presidente de la República el 28 de octubre de 2003, p.70-94.

GREBE, M. E. (1998). Culturas Indígenas de Chile: un estudio preliminar. Santiago de Chile: Pehuén.

GUNDERMANN, H. (1981). Análisis Estructural de los ritos Mapuches Nguillatún y Pintevún, Tesis para optar al grado de Licenciado en Antropología Social. Santiago de Chile: Universidad de Chile. 
LATCHAM, R. (2001). La Religión de la Antigua Tierra de Chile. Concepción: Kushe. MALINOWSKI, B. (1976). El Cultivo de la tierra y los ritos agrícolas en las Islas Trobriand. Barcelona: Labor.

MAUSS, M. (1991). Sociología y Antropología. Madrid: Editorial Tecnos.

NADEL, S. (1974). "Malinowski, sobre la Magia y la Religión", en: Firth, R.; Leach, E.; Mair, L.; Nadel, S.; Parsons, T. y otros. Hombre y Cultura. La obra de Bronislaw Malinowski. Madrid: Siglo XXI.

ORTIZ, G. (2003). La integración del caballo en la vida de los Pehuenches. Indígenas montañeses y de la pampa. Documento de trabajo no publicado.

ORTÚZAR, P. (2005). Evolución del Modelo Económico Mapuche. 600 años de subsistencia. Documento de trabajo no publicado.

PARENTINI, L. (1996). "Etnohistoria en el Área Centro-Sur: Frontera y Antropología", en: Introducción a la Etnohistoria Mapuche. Santiago de Chile: DIBAM.

POLANYI, K. (1994). El Sustento del Hombre. Madrid: Mondadori.

POLANYI, K. (1968). "Societies and Economic Systems", en: Primitive, Archaic and Modern Economies (edited by George Dalton). New York: Anchor Books.

SAHLINS, M. (1997). Cultura y Razón Práctica. Barcelona: Gedisa.

STUCHLIK, M. (1976). Rasgos de la Sociedad Mapuche Contemporánea. Temuco: Ediciones Nueva Universidad.

TÖNNIES, F. (1971). "The contrast between Gemeinschaft and Gesellschaft", en: Peter Worsley (ed.). Modern Sociology. Introductory readings. Middlesex: Penguin Books, p. 295-296.

VILLALOBOS, S. (1983). Historia del Pueblo Chileno. Tomo I. Santiago de Chile: Zig-Zag.

VILLALOBOS, S. (1989). "La Aculturación y la necesidad de comerciar", en: LoS Pehuenches en la vida fronteriza. Santiago de Chile: Pontificia Universidad Católica de Chile, p. 43-63.

WHITE, L. (1964). La Ciencia de la Cultura. Estudio sobre el Hombre y la Civilización. Buenos Aires: Paidós.

WOLF, E. R. (1982). Europe and the People without history. Los Angeles: University of California Press. 